\title{
Research Productivity of Ultrasonics in USA: A Scientometric Study
}

\author{
L.Jamuna Rani ${ }^{1}$ and C.Jayachithra ${ }^{2}$ \\ ${ }^{1}$ Librarian, CARE Group of Institutions - Trichy ${ }^{1},{ }^{2}$ Urumu Dhanalakshmi College-Trichy, Tamil Nadu India \\ E-mail: Madhumitha.trichy@gmail.com
}

\begin{abstract}
Scintometric is a branch of library and information science. Scintometric tools can be used to measure and compare the scientific activities at various levels of aggregation including institutions, sectors, provinces and countries. They can also be used to measure research collaborations, to map scientific networks and to monitor the evolution of scientific fields. In this paper mainly visualizing the scientific publication of ultrasonics during 2004-2014, indexed in the Web of Science (WoS), a renowned database published online by the Thomson International, (formerly Institute for Scientific Information), Philadelphia. Scientometrics is the study of quantitative aspect of science as a discipline. These refers to component fields related to the study of dynamics of disciplines as reflected in the production of their literature.

Keywords: Scientometrics, Research productivity, Ultrasonics, USA.
\end{abstract}

\section{I.INTRODUCTION}

Science mapping aims to reveal structures of scientific literature and underlying specialties using graphical representation. All these scientometric technologies are interlinked and having much importance in analysis the data. According to Hood and Wilson, the methods of bibliometrics are closely related specialized of scientometric and webometrics. Scientometric research has a strong application-oriented tradition (Garfield, 1979b; Raan, 1997). For example, scientometric studies may help governments and private sectors to recognize their competitive limits and make intentional plans for future research areas and assign research funding to key research areas. Scientometrics is "the study of the measurement of scientific and technological progress”.

This study emphasize on the study of growth of literature on Ultrasonics and its trend analysis. The research publication on Ultrasonics in USA and its contribution for research and development are playing a significant criteria for acquiring more funds from the authorities.

\section{II.REVIEW OF LITERATURE}

Aghafi, S., Asadi, M., \& Osareh, F(2014). The upward trend in collaborative S\&T research at the international level is significant in the present Information and Communication Technology era. The present study focuses on analysing India's strengths and weaknesses in collaborative research at the international level and collaborative fields are analysed for their macro and micro levels. The chronological trend of international collaboration, the collaborative countries, quality of the collaborative publications, collaborative fields, specialization in collaboration, etc. are the main criteria evaluated in the present work.

Schmidt, S., Bundschuh, M., Scutaru, C., Klingelhoefer, D., Groneberg, D. A., \& Gerber, A. (2013). The Novel influenza in 2009 caused by H1N1, as well as the seasonal influenza, still are a challenge for the public health sectors worldwide.. The current study used scientometric indices for a detailed investigation on influenza related research activity and the method of density equalizing mapping to make the differences of the overall research worldwide obvious. The query retrieved 51,418 publications that are listed in WoS for the time interval from 1900 to 2009. There is a continuous increase in research output and general citation activity especially since 1990. Results: The identified all in all 51,418 publications were published by researchers from 151 different countries. Scientists from the USA participate in more than 37 percent of all publications, followed by researchers from the UK and Germany with more than five percent. In addition, the USA is in the focus of international cooperation. In terms of number of publications on influenza, the Journal of Virology ranks first, followed by Vaccine and Virology. The highest impact factor (IF 2009) in this selection can be established for The Lancet (30.75). Robert Webster seems to be the most prolific author contributing the most publications in the field of influenza.

Khosrowjerdi, M., \& Bayat, M. K. (2013) This study aims to assess the nanotribology research output at global level using scientometric tools. The SCOPUS database was used to retrieve records related to the nanotribology research for the period 1996-2010. The performance of the most productive countries, institutes and most preferred journals is assessed. Various visualization tools such as the Sci2 tool and Ucinet were employed. The most preferred journals were Tribology Letters, Wear and Journal of Japanese Society of Tribologists. The result of author keywords analysis reveals that Molecular Dynamics, MEMS, Hard Disk and Diamond like Carbon are major research topics.

Fricke, R., Uibel, S., Klingelhoefer, D., \& Groneberg, D. A. (2013) Nanobiopharmaceutcs is a good example of the convergence technologies and it is an important means of synergy and integration of technology convergence. This study takes use of scientometric method and indexes to 
analyze the international status and power distribution in the field. A few papers about bibliometrics make use of the knowledge of the calculus.

Wang, M.-H., Fu H.Z., \& Ho, Y.S.,(2011) has discussed the scientific performance of National Taiwan University (NTU) and Peking University (PKU) were compared by two indicators, namely citations per publication and h-index, based on the information extracted from the SCI, SSCI, and A\&HCI from 2000 to 2009. Analyzed aspects covered publication outputs, publication patterns, and international and inter-institutional collaborations of the two universities.

Inglesi-Lotz and Pouris (2011)2 investigated scientometrically the effect of the NRF on the output of the South African Social Science Researchers for the period 1981-2006. Their performance is measured by the number of research publication. The observation shows a positive impact of the NRF programe on the research output of Social Science researchers and the adaptation of the programme has greatly influenced in population of research articles by a healthy average of 24.5 percent.

\section{III.ULTRASONICS}

Ultrasonics plays an essential role in our day to day life. Ultrasonic is an adjective referring to ultrasound. Ultrasound is defined by the American National Standards Institute as " Sound at frequencies greater than $20 \mathrm{kHz}$. Subsequently the associated high volume of energy consumption has become a major concern both economically and environmentally.

\section{Properties of ultrasonic waves:}

1. These waves have very high frequency due to which they contain a large amount of energy.

2. The velocity of ultrasonic waves increases with the increase in frequency

3. Ultrasonic waves can be transmitted over long distances due to negligible loss of energy

4. Intense ultrasonic waves produce disruptive effect on liquids by causing bubbles to be formed.

\section{Applications of ultrasonic waves:}

The Ultrasonic waves are used in understanding the following:
a. Depth of sea
b. Signaling
c. Heating effects
d. Mechanical applications
e. Detection of cracks in metals
f. Formation of alloys
g. Chemical applications
h. Ultrasonography
i. Ultrasonic cleaning
j. Medical applications.

\section{IV.OBJECTIVES OF THE STUDY}

The main aim of this study is to know the publication productivity through Scientometrics and to search out the furthers scope and area for research. To examine the research productivity of Ultrasonics in USA, as reflected in the publication output during 2004-2014.

1. To analyse the research output of ultrasonics in USA.

2. To understand the patterns of collaboration and major collaborative partners.

3. To know the publications productivity of leading institutions in USA on ultrasonic study.

4. To trace out the most prolific authors of the ultrasonic research in USA

5. To find out the patterns of research Publications in top 10 journals.

\section{V.METHODOLOGY}

Data were collected from the science citation index (SCI) which is available through Web of Science(WoS) The WoS is the search platform provided by Thomson Reuters (the former Thomson Scientific Emerged from the Institute for scientific Information (ISI) in Philadelphia. SCI database is one of the very comprehensive database covering all aspects of science.

The publication of ultrasonics in USA during the period of 2004-2014 is analysed. The search string "Ultrasonics” in the "Basic Search" field of WoS was used to download the records on the subject. Total of 6845 records were downloaded and analyzed using the Histcite software application.

\section{VI.ANALYSIS OF DATA}

Keywords are one of the best scientometric indicators to understand and grasp instantaneously the thought content of the papers and to find out the growth of the subject field. Analysis keywords appeared either on the title or assigned by the indexer or the author himself who will help in knowing in which direction the knowledge grows. The high frequency keywords will enable us to understand the various aspects of Ultrasonics under study. The high frequency keywords were : Ultrasonic 2217 (32.39\%), Ultrasound 557 ( 8.14\%), Acoustic 351 (5.13\%), Wave 302 (4.41\%), and Laser 159 (2.32\%). 
TABLE I TOP TEN PRODUCTIVE JOURNALS WITH RESPECT TO THE NUMBER OF ARTICLES DEALING WITH ULTRASONICS

\begin{tabular}{|c|c|c|c|c|}
\hline S.No. & Journal & Records & TLCs & TGCs \\
\hline 1 & $\begin{array}{l}\text { IEEE transactions on ultrasonics } \\
\text { ferroelectrics and frequency control }\end{array}$ & 286 & 753 & 3912 \\
\hline 2 & $\begin{array}{l}\text { Journal of the acoustical society of } \\
\text { america }\end{array}$ & 273 & 622 & 3190 \\
\hline 3 & Ultrasonics & 161 & 184 & 1422 \\
\hline 4 & Ultrasound in medicine and biology & 131 & 215 & 2132 \\
\hline 5 & Journal of applied physics & 113 & 18 & 1176 \\
\hline 6 & Applied physics letters & 111 & 40 & 1326 \\
\hline 7 & Materials evaluation & 97 & 53 & 187 \\
\hline 8 & Medical physics & 60 & 49 & 711 \\
\hline 9 & Journal of endodontics & 59 & 166 & 1187 \\
\hline 10 & Journal of biomedical optics & 56 & 0 & 805 \\
\hline & TOTAL & 1347 & 2100 & 16048 \\
\hline
\end{tabular}

TABEL II DISTRIBUTION OF RECORDS ON THE BASICS OF KEYWORDS

\begin{tabular}{|c|l|c|c|c|}
\hline S.No. & Word & Records & TLCs & TGCs \\
\hline 1 & Ultrasonic & 2217 & 3473 & 23146 \\
\hline 3 & Ultrasound & 557 & 740 & 10462 \\
\hline 6 & Acoustic & 351 & 393 & 4353 \\
\hline 7 & Wave & 302 & 465 & 3237 \\
\hline 2 & Laser & 159 & 69 & 1815 \\
\hline 4 & Piezoelectric & 155 & 188 & 2406 \\
\hline 5 & Carbon & 153 & 141 & 3379 \\
\hline 8 & Pressure & 134 & 191 & 1643 \\
\hline 9 & Composite & 125 & 107 & 1461 \\
\hline 10 & Nanoparticles & 96 & 102 & 2803 \\
\hline
\end{tabular}

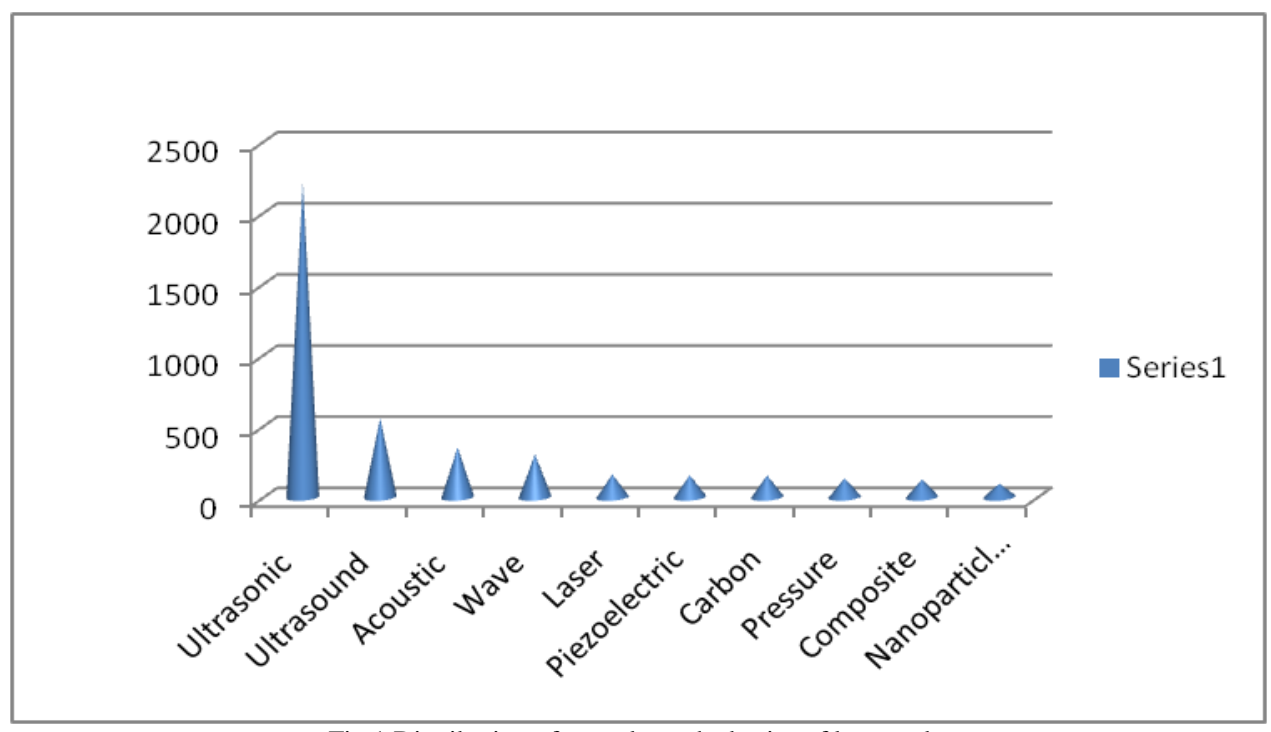

Fig.1 Distribution of records on the basics of keywords 
TABLE III YEAR-WISE DISTRIBUTION OF DOCUMENTS

\begin{tabular}{|c|c|c|c|c|c|c|c|c|c|}
\hline S.No. & $\begin{array}{c}\text { Publication } \\
\text { Year } \\
\end{array}$ & $\begin{array}{l}\text { No. of } \\
\text { Recs. }\end{array}$ & $\begin{array}{c}\text { Cumulativ } \\
\text { e Recs. }\end{array}$ & $W_{1}$ & $w_{2}$ & $\begin{array}{c}\text { Difference } \\
\mathbf{R} \\
\end{array}$ & $\begin{array}{c}\text { Mean } \\
\left(w_{1}-w_{2}\right) \\
\end{array}$ & $\begin{array}{c}\text { Doubling } \\
\text { Time }\end{array}$ & $\begin{array}{c}\text { Mean of } \\
\text { DT }\end{array}$ \\
\hline 1 & 2004 & 601 & 601 & 0 & 6.39 & -6.39 & \multirow{3}{*}{-6.31} & -0.108 & \multirow{3}{*}{15.364} \\
\hline 2 & 2005 & 587 & 1188 & 6.39 & 6.37 & 0.02 & & 34.65 & \\
\hline 3 & 2006 & 555 & 1743 & 6.37 & 6.31 & 0.06 & & 11.55 & \\
\hline 4 & 2007 & 620 & 2363 & 6.31 & 6.42 & -0.11 & \multirow{3}{*}{-0.05} & -6.3 & \multirow{3}{*}{15.225} \\
\hline 5 & 2008 & 593 & 2956 & 6.42 & 6.38 & 0.04 & & 17.325 & \\
\hline 6 & 2009 & 582 & 3538 & 6.38 & 6.36 & 0.02 & & 34.65 & \\
\hline 7 & 2010 & 591 & 4129 & 6.36 & 6.38 & -0.02 & \multirow{3}{*}{-0.04} & -34.65 & \multirow{3}{*}{-7.425} \\
\hline 8 & 2011 & 683 & 4812 & 6.38 & 6.52 & -0.14 & & -4.95 & \\
\hline 9 & 2012 & 658 & 5470 & 6.52 & 6.48 & 0.04 & & 17.325 & \\
\hline 10 & 2013 & 684 & 6154 & 6.48 & 6.52 & -0.04 & \multirow{2}{*}{-0.025} & -17.325 & \multirow{2}{*}{-43.313} \\
\hline 11 & 2014 & 691 & 6845 & 6.52 & 6.53 & -0.01 & & -69.3 & \\
\hline & TOTAL & 6845 & & & & & & & \\
\hline
\end{tabular}

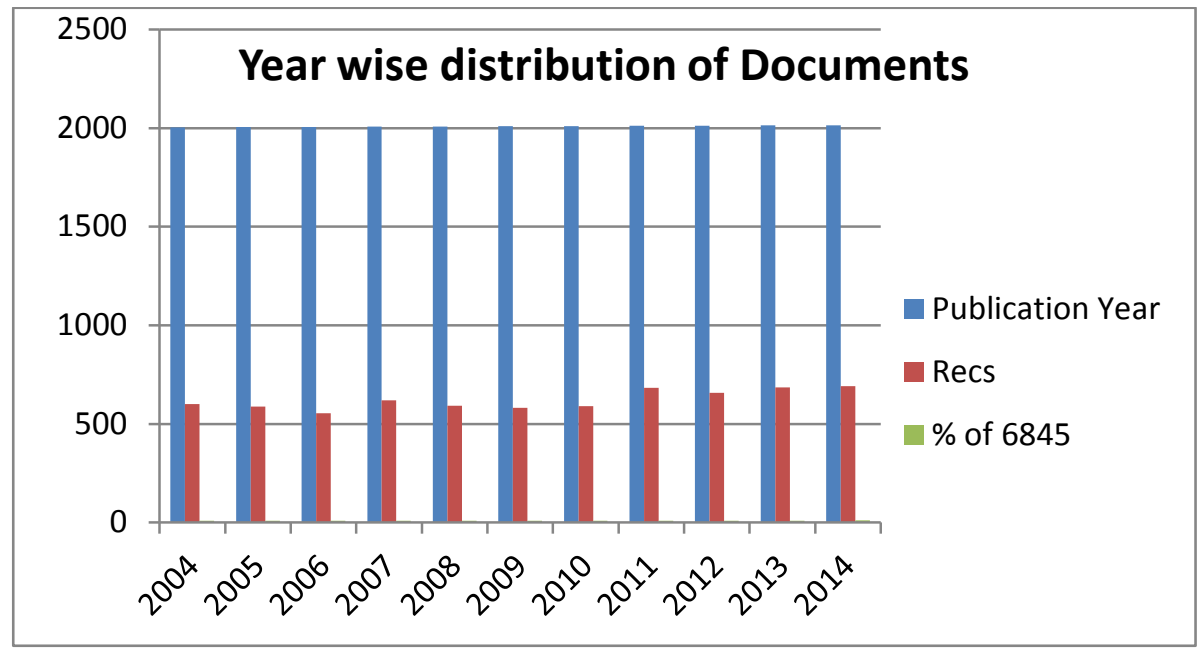

Fig. 2 Year-wise distribution of Documents

TABLE IV DOCUMENT TYPE-WISE DISTRIBUTION OF PUBLICATIONS

\begin{tabular}{|c|l|c|c|c|c|}
\hline S.No. & \multicolumn{1}{|c|}{ Document Type } & Recs & $\begin{array}{c}\mathbf{\%} \text { of } \\
\mathbf{6 8 4 5}\end{array}$ & TLCs & TGCs \\
\hline 1 & Article & 5863 & 85.65 & 6774 & 81419 \\
\hline 2 & Article; Proceedings Paper & 468 & 6.84 & 535 & 6225 \\
\hline 3 & Review & 254 & 3.71 & 530 & 11011 \\
\hline 4 & Meeting Abstract & 165 & 2.41 & 5 & 22 \\
\hline 5 & Editorial Material & 59 & 0.86 & 33 & 320 \\
\hline 6 & Letter & 18 & 0.26 & 15 & 58 \\
\hline 7 & Review; Book Chapter & 8 & 0.12 & 27 & 490 \\
\hline 8 & Correction & 4 & 0.06 & 0 & 0 \\
\hline 9 & News Item & 2 & 0.03 & 0 & 5 \\
\hline 10 & Reprint & 2 & 0.03 & 0 & 8 \\
\hline 11 & Article; Book Chapter & 1 & 0.01 & 0 & 10 \\
\hline 12 & Biographical-Item & 1 & 0.01 & 0 & 3 \\
\hline & & 6845 & 100 & 7919 & 99571 \\
\hline
\end{tabular}


The research treand of ultrasonics publications in USA was analysed with the help of WoS. It is found from the above table that the maximum of 691 records were viewed from WoS for the year 2014. It is as low as 555 in the year 2006. The calculation made for relative growth rate and doubling time to understand the level of growth of the publication productivity of ultrasonics. It is observed from the table that the relative growth rate is in the trend which was -6.39 in 2004 to -0.01 in the year of 2014 . The mean relative growth for the period 2004-2006 was -6.31 to -0.02 during the period 2013-14. The overall study period has witnessed a mean relative growth rate as -6.42 . The doubling time for the ultrasonics research has decreased from 15.3 during 2004-2006 to -43.31 during 2013-14. It is inferred from the table that there is a very little micro level increase in the relative growth rate. The doubling time is also not able to estimate with the short span of time (10 Years).

Table 4 reveals the Publications in its Document type. The highest number of publications were 5863 (85.65\%) in the form of journal articles with 6774 Local Citation Scores and 81419 Global Citation Scores. Next to this, 468 (6.84\%) in Proceedings paper, with 535 Local Citation Scores and 6225 Global Citation Scores. The reviews 254 (3.71\%) 530 Local Citation Scores and 11011 Global Citation Scores and Meeting Abstracts 165 (2.41\%), 5 Local Citation Scores and 22 Global Citation Scores and Editorial Material 59 (0.86\%), Letter $18(0.26 \%)$ Review; Book Chapter 8 $(0.12 \%)$ in Correction, 4 (0.06\%) in News Item, and Reprint $2(0.03 \%)$. And in Article; Book Chapter and BiographicalItem $1(0.01 \%)$.

The inference is that the maximum number of publication preferred by the scholars including faculty from the Ultrasonics Researchers was found to be the journal articles and the remaining items formed a negligible percentage. The global citation rate exceeded the local citation rates and the inference is that the visibility of the publications while compared to that of the local citation rates.

TABLE V DISTRIBUTION OF THE RECORDS IN THE TOP TEN INSTITUTIONS
\begin{tabular}{|c|l|c|c|c|}
\hline S.No. & \multicolumn{1}{|c|}{ Institution } & Recs & TLCs & TGCs \\
\hline 1 & University of Illinois & 248 & 456 & 4065 \\
\hline 2 & Penn State University & 212 & 218 & 2929 \\
\hline 3 & $\begin{array}{l}\text { Georgia Institute of } \\
\text { Technology }\end{array}$ & 194 & 393 & 5136 \\
\hline 4 & University So California & 179 & 329 & 2549 \\
\hline 5 & University Wisconsin & 173 & 262 & 2444 \\
\hline 6 & Washington University & 162 & 352 & 4287 \\
\hline 7 & University of Michigan & 153 & 170 & 2030 \\
\hline 8 & Ohio State University & 132 & 178 & 1742 \\
\hline 9 & Stanford University & 131 & 275 & 2059 \\
\hline 10 & Iowa State University & 130 & 97 & 1037 \\
\hline
\end{tabular}

The above table shows the details on publication productivity of top 10 Institutions. University of Illinois is top ranking Institution with 248 (3.62\%) Publication followed by Penn State University with 212 (3.10\%), Georgia Institute of Technology with 194 (2.83\%), and University So California with 179 (2.62\%) publications.

\begin{tabular}{|} 
TABLE VI COUNTRY-WISE DOCUMENTS DISTRIBUTION \\
\begin{tabular}{|c|l|c|c|c|c|}
\hline S.No. & Country & Recs & $\begin{array}{c}\mathbf{\%} \text { of } \\
\mathbf{6 8 4 5}\end{array}$ & TLCs & TGCs \\
\hline 1 & USA & 6441 & 94.09 & 7630 & 93696 \\
\hline 2 & Peoples R China & 415 & 6.06 & 213 & 4393 \\
\hline 3 & Unknown & 280 & 4.09 & 198 & 3261 \\
\hline 4 & South Korea & 242 & 3.54 & 180 & 2993 \\
\hline 5 & Canada & 191 & 2.79 & 222 & 3167 \\
\hline 6 & France & 171 & 2.50 & 194 & 2522 \\
\hline 7 & Germany & 165 & 2.41 & 145 & 2920 \\
\hline 8 & UK & 164 & 2.39 & 147 & 3379 \\
\hline 9 & Japan & 151 & 2.21 & 69 & 1716 \\
\hline 10 & Italy & 105 & 1.53 & 208 & 3170 \\
\hline
\end{tabular}
\end{tabular}




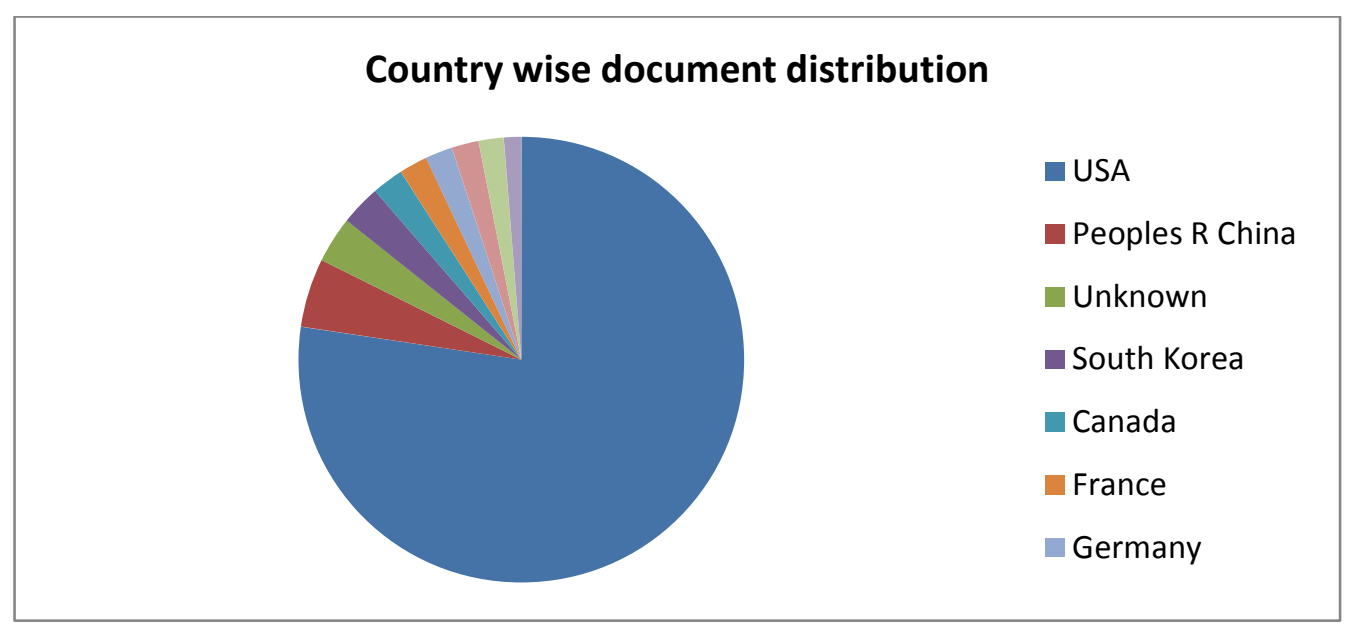

Fig. 4 Country-wise documents distribution

Eighty Five (85) publications from various countries were collaborated with USA for research productivity of Ultrasonics. Table 6 shows the details of publishing articles and research work on ultrasonics.

It is found from this analysis, China (6.06\%), South Korea (3.54\%) , and Canada (2.79 \%) are the countries having more number of records published in collaboration with USA (94.09\%) records in highest percentage of Ultrasonics research. With regard to TLCs and TGCs citation scores, USA has scored maximum its scores. Next to this by China, South Korea, Canada, France, Germany, UK, Japan, Italy respectively.

TABLE VI TOP 10 PRODUCTIVE AUTHORS WITH RESPECT TO THE RESEARCH PRODUCTIVITY ON ULTASONICS (WOS)

\begin{tabular}{|c|c|c|c|c|c|}
\hline S.No. & Author & Records & $\begin{array}{c}\text { \% of } \\
\mathbf{6 8 4 5}\end{array}$ & TLCs & TGCs \\
\hline 1 & Shung KK & 113 & 1.65 & 267 & 1586 \\
\hline 2 & Zhou QF & 67 & 0.98 & 176 & 919 \\
\hline 3 & Wang LHV & 50 & 0.73 & 144 & 2389 \\
\hline 4 & Khuri-Yakub BT & 48 & 0.70 & 2188 & 914 \\
\hline 5 & Isayev AI & 44 & 0.64 & 81 & 453 \\
\hline 6 & Li BS & 42 & 0.61 & 126 & 610 \\
\hline 7 & Rose JL & 39 & 0.57 & 79 & 497 \\
\hline 8 & Suslick KS & 39 & 0.57 & 173 & 1369 \\
\hline 9 & di Scalea FL & 38 & 0.56 & 113 & 682 \\
\hline 10 & Holland MR & 38 & 0.56 & 114 & 329 \\
\hline
\end{tabular}

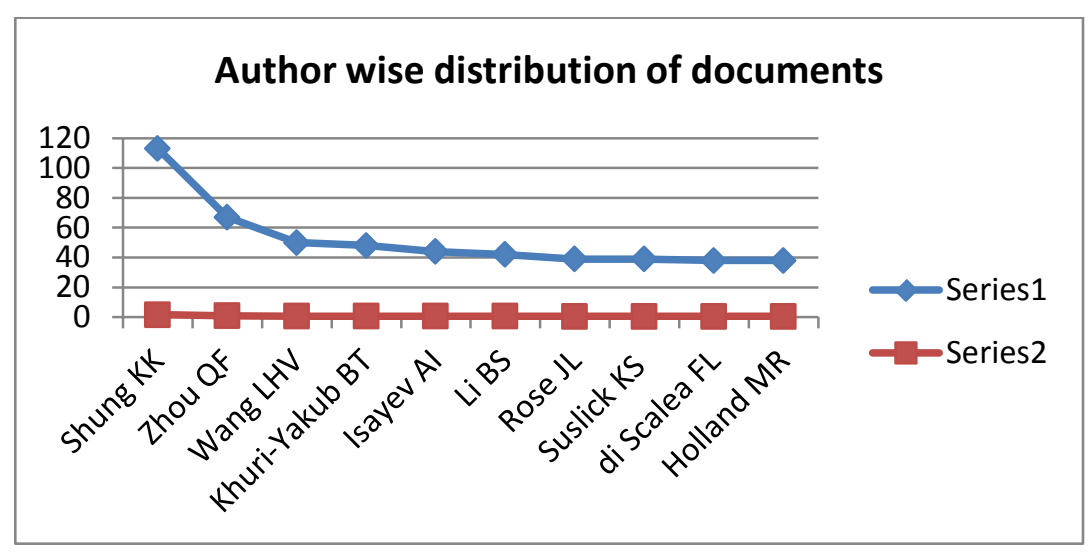

Fig.5 Author wise distribution of document 
Out of 17985 authors, "Shung KK" has published the maximum number of articles as 113 articles (1.65\%), with 267 TLCS, and 1586 TGCS and it is ranked first in the research output in the field of Ultrasonics. The author "Zhou QF" has published 67 articles (0.98\%) with 176 TLCS, and 919 TGCS and he stood in the second rank of research output. The author "Wang LHV' has published 50 articles (0.73\%), with 144 TLCS, 2389 TGCS. His output is ranked in third place.

It could be found from this analysis that "Shung KK", "Zhou QF" and "Wang LHV" is the prolific authors among the total of 17985 authors.

\section{VII.FINDINGS}

1. It is found from the analysis that the most productive journal is "IEEE transactions on ultrasonics ferroelectrics and frequency control” with 286 papers published in the topic with Ultrasonics.

2. The high frequency keywords were in the research productivity on "Ultrasonic" were: Ultrasonic 2217 (32.39\%), Ultrasound 557 ( 8.14\%), Acoustic 351 (5.13\%), Wave 302 (4.41\%), and Laser 159 (2.32\%).

3. It is observed that $85.65 \%$ of the literature was published in journals as articles followed by $6.84 \%$ in proceeding paper.

4. University of Illinois is top Institution with the maximum of 248 (3.62\%) publication on the topic "Ultrasonics".

5. USA is top producing country with 6441(94.09\%) followed by China with 415 publications (6.06\%).

6. The most productive author is Shung KK with 113 papers related to Ultrasonics.

\section{VIII.CONCLUSION}

The study of metric analysis by using the various measuring technique such as bibliometrics, Scientometrics, citation analysis and almetrics are playing the vital role in identifying the research productivity of the Institution, Individual on special topics. This study emphasize on the study of growth of literature on Ultrasonics and its trend analysis. The research publication on Ultrasonics in USA and its contribution for research and development are playing as significant criteria for acquiring more funds from the authorities.

\section{REFERENCES}

[1] Aghafi, S., Asadi, M., \& Osareh, F. (2013). Historiographical map of Iranian engineering scientific publications during 1939-2011. International Journal of Information Science and Management, 11(2), 1-24.

[2] Schmidt, S., Bundschuh, M., Scutaru, C., Klingelhoefer, D., Groneberg, D. A., \& Gerber, A. (2013). Hepatitis B: Global scientific development from a critical point of view. Journal of Viral Hepatitis.

[3] Khosrowjerdi, M., \& Bayat, M. K. (2013). Mapping the interdisciplinarity in scientometric studies. Iranian Journal of Information Processing Management, 28(2), 393-409.

[4] Fricke, R., Uibel, S., Klingelhoefer, D., \& Groneberg, D. A. (2013). Influenza: A scientometric and density-equalizing analysis. BMC Infectious Diseases, 13(1).

[5] Wang, M.-H., Fu H.Z., \& Ho, Y.S.,(2011). Scientometrics study of scientific productions of Iranian Medical Sciences Universities in Web of Science During 1999-2008. Medical Information Sciences and Technology. Vol. 26, Issue 2, 2011, pp. 355-371.

[6] Roula Inglesi-Lotz and Anastassios Pouris (2011). Scientometric impact assessment of a research policy instrument: the case of rating researchers on scientific outputs in South Africa. Scientometrics. 88,pp.747-760. 